\title{
A New Fault Diagnosis Approach for Brushless Doubly Fed Machines for Wind Turbine Generator Applications
}

\author{
S. Abdi, M. Tatlow, E. Abdi, R. McMahon, S. Amiri
}

\begin{abstract}
The Brushless Doubly Fed Machine (BDFM) with high reliability and robust structure demonstrates commercial and technical advantages both as a generator and motor for variable speed applications. As a generator it is particularly attractive to be used in offshore wind turbines where reliability improvement and maintenance cost reduction are the key factors in market growth. As a motor it may be utilized for adjustable speed drives. In this study, a continuous wavelet transform (CWT) technique using a wavelet-based adoptive filter has been proposed for the BDFM fault detection as a generator operating in a wind turbine. Three different generator-typed faults namely rotor torque perturbation, rotor broken bar and grid overvoltage faults have been considered to assess the practicality of the proposed technique. The study has been performed on a D400 $250 \mathrm{~kW}$ BDFM.
\end{abstract}

Index Terms-- Brushless Doubly Fed Machine (BDFM), Continuous Wavelet Transform (CWT), Condition Monitoring, Fault Diagnosis, Rotor Broken Bar, Torque Perturbation.

\section{INTRODUCTION}

$\mathrm{T}$ HERE has been a dramatic increase in the size of wind turbines from $30 \mathrm{~kW}$ up to $10 \mathrm{MW}$ Over the past 50 years [1]. To date, several generator concepts have been considered for offshore wind where there is a great wind power resource and hence significant future market growth is expected. These are permanent magnet generators, doubly fed induction generators, superconducting generators and high voltage DC generators [2]. To reduce the cost of energy from wind turbines, there is a need to improve availability and reduce operational and maintenance costs. Brushless Doubly Fed Machines (BDFMs) are an attractive solution for wind power generation as they offer promising design features and performance characteristics such as brushless operation, slip-ring elimination, fractionally rated power electronic converter and medium-speed operation [3]. Other applications have also been reported for the BDFM, for example, in a flywheel energy storage system [4] and as a ship generator [5].

The BDFM consists of two stator windings designed with different pole-pair numbers, one is connected directly to the

S. Abdi is with the School of Engineering, University of East Anglia (UEA), Norwich, UK (e-mail: s.abdi-jalebi@uea.ac.uk).

M. Tatlow is with McLaren Technology Centre, Surrey, UK (e-mail: mark.tatlow@mclaren.com)

E. Abdi is with Wind Technologies Limited, St John's Innovation Centre, Cambridge, UK (e-mail: ehsan.abdi@windtechnologies.com).

R. McMahon is with Warwick Manufacturing Group (WMG), Warwick University, Coventry, UK (e-mail: r.mcmahon.1@warwick.ac.uk)

S. Amirt is with the Faculty of Engineering, Coventry University, Coventry, UK (e-mail: ad0246@coventry.ac.uk) grid called the Power Winding (PW) and the other is supplied through a variable-voltage variable-frequency converter called the Control Winding $(\mathrm{CW})$. A schematic of the BDFM grid connection is shown in Fig. 1. The PW and CW pole-pair numbers are chosen in such a way to eliminate direct magnetic coupling between the two windings. The indirect coupling is enabled using a special rotor structure called the nested-loop rotor. A nested-loop rotor configuration for the BDFM is shown in Fig. 2. The number of nests required for the rotor can be obtained from:

$$
N_{n}=p_{1}+p_{2}
$$

where $p_{1}$ and $p_{2}$ are $\mathrm{PW}$ and $\mathrm{CW}$ pole-pair numbers, respectively.

The BDFM can operate in three distinct modes of operation including: induction, cascaded and synchronous. In all modes, the PW is directly connected to the supply, while the $\mathrm{CW}$ is opened in the induction mode, shortened in the cascaded mode and supplied through a fractionally rated convertor in the synchronous mode. The BDFM rotational speed can be calculated from:

$$
\omega_{r}=\frac{\omega_{1}+\omega_{2}}{p_{1}+p_{2}}
$$

where $\omega_{1}$ and $\omega_{2}$ are PW and CW supply angular frequencies, respectively.

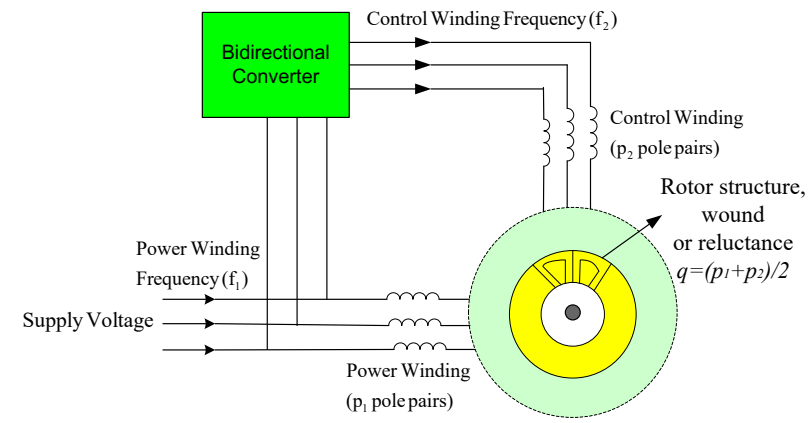

Fig. 1. A schematic of the BDFM grid connection

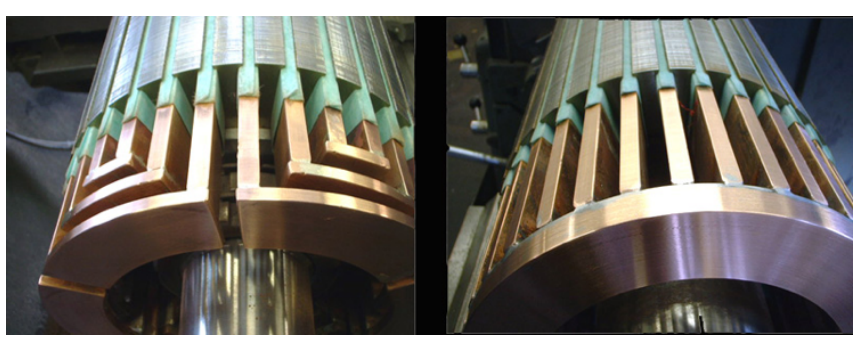

Fig. 2. The nested-loop rotor structure. 
Aside from developing more advanced wind turbines and generator technologies to improve availability, an effective way to achieve the improvement is to apply reliable and costeffective condition monitoring [6]. The wind industry currently uses condition monitoring systems (CMSs) such as vibration, temperature, lubricating oil, and generator current analysis developed from other rotating machine power generation industries [7], where they have achieved success. However, these techniques have not yet proven effective in wind turbines, which are operated at slow speed and with a rapidly varying torque. Commercial wind turbine CMSs mostly employ vibration-based techniques using accelerometers, which are sophisticated and expensive. Lubrication oil analysis is becoming more common for detecting gearbox tooth and bearing wear but cannot detect failures outside the gearbox [8]. More advanced techniques, such as optical strain measurements have been developed for monitoring blade integrity. However, these are also expensive, and recent reliability surveys [9] have shown that the electrical systems have a higher failure rate than the mechanical systems.

There are only few studies carried out on fault diagnosis of the BDFM, mostly on vibration analysis and mitigation. Logan et. al. [10] derived equations for vibration components magnitudes generated by the PW and CW magnetic fields as functions of air-gap flux density, pole numbers and machine dimensions. Abdi et. al. in [11] proposed a new parallel winding design for the stator $\mathrm{PW}$ and $\mathrm{CW}$ to mitigate the vibration level in the presence of rotor eccentricity. Dorrell et. al. in [12] proposed a number of rotor designs with suitable stator pole pair combinations in order to improve the BDFM design by reducing the unbalanced magnetic pull (UMP). Afshar et. al. in [13] recently proposed a new fault detection technique based on the machine's current signature analysis to detect rotor eccentricity faults in the BDFM. In [14] a new method was proposed in order to detect the stator winding short circuit faults in the BDFM by analysing the nested loop rotor slot harmonics seen in the stator currents. In [15] an analytical method of the BDFM with broken rotor loops and end rings was presented. Nevertheless, in none of the above work was a generic technique for detecting various types of faults in the BDFM as a wind turbine generator proposed.

Watson et. al [16] have proposed novel CMS techniques based on the continuous wavelet transform (CWT) of the generator's electrical power signal to detect individual vibration faults that occur in each mechanical component, with both frequency and time duration. By comparing the real-time vibration waveforms obtained from the CWT with a previous calculation the fault and its specific frequency may be detected. This technique is still in the research stage and has only been applied to generators in a laboratory environment butit does appear to offer significant advantages compared to traditional techniques. For instance, it uses existing sensors available in most generator systems to measure electrical signals. Therefore, it would be a nonintrusive method with easy implementation and no additional costs. In addition, the specific frequencies associated to the fault as well as the time that the fault occurs can be identified. This helps determine the location and reason of the fault. The CWT also has the ability to detect both electrical and mechanical faults occurred in a wind turbine. Although, the use of wavelet transform method in detecting various forms of faults in wind turbine generators have been widely studied [17, 18], to the best of the authors' knowledge, no work has been reported in applying this technique to the BDFM.

In this paper the practicality of the CWT method in detecting various faults in the BDFM is assessed. A simulation model is developed in MATLAB/Simulink for a prototype D400 $250 \mathrm{~kW}$ BDFM and its accuracy in predicting the machine's performance at different operating conditions is validated using experimental tests. A wavelet based adoptive filter is designed and implemented on the simulation models in order to reduce the computational time. Three different fault types namely the torque perturbation, rotor broken bar and grid overvoltage faults are being considered in this work in order to assess the practicality of the proposed CWT method.

\section{Continuous Wavelet Transform (CWT) Method}

\section{A. Choice of Wavelet Function}

Similar to the Fourier Transform, the CWT uses inner products to measure the similarity between a signal and an analysing function [16]. In the CWT, the analysing function is a wavelet. The CWT compares the signal with a shifted and compressed or stretched version of a wavelet. Stretching or compressing a function is referred to as 'scaling'. By comparing the signal to the wavelet at various scales and positions, a function of two variables is obtained. If the signal is real-valued, the CWT is a real-valued function of scale and position. The CWT of a real-time signal $x(t)$ can be defined as [19]:

$$
\operatorname{CWT}(b, a)=\frac{1}{\sqrt{a}} \int_{-\infty}^{\infty} x(t) \psi^{*}\left(\frac{t-b}{a}\right) d t
$$

where $\psi(t)$ is the mother wavelet and can be expressed as:

$$
\psi_{a, b}(t)=\frac{1}{\sqrt{a}} \psi\left(\frac{t-b}{a}\right) \quad a, b \in R, \quad a \neq 0
$$

where $a$ and $b$ represent the parameters of the wavelet scale and time-shift, respectively. The asterisk ' $* 1$ is used for complex conjugate.

The wavelet transform results in coefficients, which reflect the correlation between the signal and the selected wavelet function. To increase the coefficient amplitudes generated by a given fault and hence enhance the fault detection process, the wavelet function should be selected based on the fault response. There are many different wavelets that can be used in the CWT. Depending on the fault type, there is a degree of freedom to select a wavelet function. For example, if the effect of a fault is going to be reflected as oscillation in the measured signal, a wavelet function that more closely matches oscillation behaviour must be chosen. The Morlet wavelet function has been 
shown to be an appropriate choice for the electrical and mechanical faults occurred in a wind turbine and therefore can be used in fault detection of the BDFM in wind turbine operating conditions [19]. The Morlet wavelet is defined as:

$$
\psi(t)=\pi^{-1 / 4} e^{-t^{2} / 2} \cos \left(\omega_{0} t\right)
$$

\section{B. Design of a Wavelet-Based Adaptive Filter}

Similar to the concept of frequency, scale is another useful property of signals in wavelet transform method [18]. The choice of scale factor, $a$ is dependent on the frequency of interest. The smaller the scale factor, the more compressed the wavelet. Also, the larger the scale, the more stretched the wavelet. In addition, there is an inverse relationship between scale and frequency. The higher scales correspond to the more stretched wavelets. The more stretched the wavelet, the longer the portion of the signal with which it is being compared, and therefore the coarser the signal features measured by the wavelet coefficients.

The conventional approach to the use of CWT is to analyse the complete bandwidth of the signal leading to a computationally intensive process, whereas, many of the calculations are unnecessary for an electrical machine condition monitoring [7]. This is because the fault-related frequencies are few and known and other frequency bands do not require analysis. Yang. et al [20] has proposed a more efficient adaptive CWT-based filter for use in real-time condition monitoring where the processing time is key. In this approach only energy at known fault frequencies is extracted and other unrelated frequencies are left unprocessed. This leads the calculation time to be significantly shorten in compare with a conventional CWT. The method is hence applied to the BDFM CWT condition monitoring in this analysis.

An adaptive, two-dimensional, time-frequency sliding window, shown in Fig. 3, is used in this paper. Its central frequency, $\omega_{c}$, is the mean frequency during the time interval, $T_{s}$, of the prescribed fault-related frequency band. The upper and lower cut-off frequencies $\omega_{\text {upper }}$ and $\omega_{\text {lower }}$ are adapted to the fluctuation of the generator rotational speed $\omega_{g}$ in the interval $T_{s}$.

$$
\left\{\begin{array}{c}
\omega_{\text {upper }}=\omega_{c}+\omega_{f} / 2 \\
\omega_{\text {lower }}=\omega_{c}-\omega_{f} / 2 \\
\omega_{f}=\eta \omega_{g}
\end{array}\right.
$$

For a wind turbine, $\omega_{f}$ is intrinsically dependent on the fluctuation of wind speed, $\eta$. The relationship between frequency $\omega$ and wavelet scale $a$ is:

$$
a=\frac{\omega_{0}}{\omega}
$$

With the aid of (6) and (7), the wavelet scales for conducting bandpass filtering can be determined by:

$$
a \in\left[\begin{array}{ll}
a_{\min } & a_{\max }
\end{array}\right]
$$

where:

$$
\left\{\begin{array}{l}
a_{\text {min }}=\frac{\omega_{0}}{\omega_{\text {upper }}} \\
a_{\text {max }}=\frac{\omega_{0}}{\omega_{\text {lower }}}
\end{array}\right.
$$

Subsequently, by performing the CWT locally in the scale range defined by (8), a matrix of wavelet coefficients can be obtained. The energy, $A$, of the frequency of interest during the period, $T_{s}$, is characterized by:

$$
\begin{aligned}
& A\left(t_{0}+T / 2\right) \\
& =\max \left(\left|C W T_{\text {local }}(a, b)\right|\right) \quad\left\{\begin{array}{c}
a \in\left[a_{\text {min }}, a_{\text {max }}\right] \\
a \in\left[t_{0}, t_{0}+T_{s}\right]
\end{array}\right.
\end{aligned}
$$

The sliding window is then moved along the signal, the maximum and minimum wavelet scales in (9) being redefined within each time interval according to the generator rotational speed $\omega_{f g}$ and (7). The energy, $A$ in the fault-related frequency band is calculated in each time interval using (3) and (10). These calculations are repeated until the whole signal has been processed. Finally, a plot of the energy variation in the fault-related frequency band is obtained with respect to time variation, and the changes in the running conditions of the WT can be assessed.

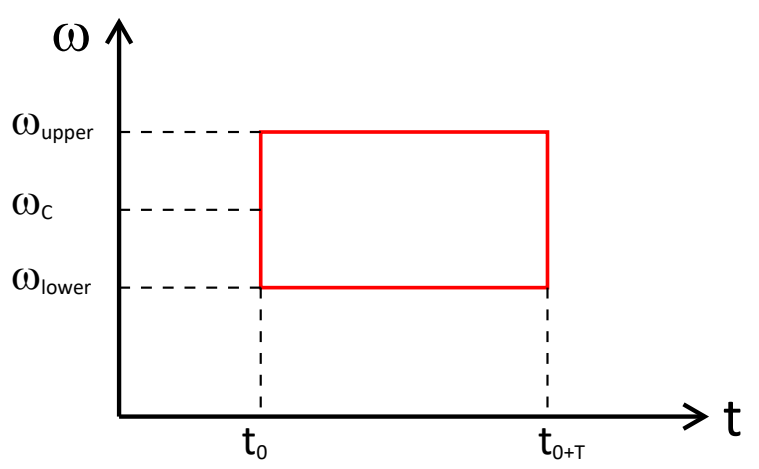

Fig. 3. The 2-D sliding window proposed for the wavelet-based adaptive filter

\section{Power Signal Sampling Frequency}

In [21] the drive train components, which are most prone to failure in a geared wind turbine, were determined. These are the blades, main bearing, shaft, gearbox and generator. The frequency ranges where the fault signature frequencies are placed, are presented in Table I [22]. To detect a wind turbine fault, the CWT is applied to the output power signal of the generator. The sampling frequency should be chosen to be twice the highest fault frequency that the system is expected to detect according to the Nyquist criterion [16]. It is therefore observed from Table I that a sampling frequency of $>202 \mathrm{~Hz}$ must be used in the CWT method.

\section{PROTOTYPE $250 \mathrm{KW}$ D400 BDFM}

The specifications of the 250kW D400 BDFM are shown in Table II. The D400 BDFM was constructed as a steppingstone toward a MW-scale wind turbine generator in Cambridge with the stack length of $820 \mathrm{~mm}$. The stator windings were form-wound from copper strips. The power winding was rated at $690 \mathrm{~V}, 178 \mathrm{~A}$, at $50 \mathrm{~Hz}$ and the control 
winding was designed for $620 \mathrm{~V}$ at $18 \mathrm{~Hz}$ and rated at $73 \mathrm{~A}$. Both stator windings were connected in delta. The rotor comprises six sets of nests each consisting of a number of concentric loops, the conductors being solid bars with one common end ring [23]. The D400 BDFM on a test bed is shown in Fig. 4.

TABLE I

FREQUENCY RANGES FOR THE MOST FREQUENT Wind TURBINE FAULTS

\begin{tabular}{|c|c|}
\hline $\begin{array}{l}\text { Range of } \\
\text { Frequency }\end{array}$ & Most frequent wind turbine faults \\
\hline $100 \pm 1 \mathrm{~Hz}$ & Generator stator and grid imbalance faults \\
\hline $50 \pm 1 \mathrm{~Hz}$ & Faults occurring in the whole WT drive train \\
\hline $25-32.5 \mathrm{~Hz}$ & $\begin{array}{l}\text { Mechanical faults caused by unbalanced blades and/or } \\
\text { shaft }\end{array}$ \\
\hline $2-30 \mathrm{~Hz}$ & $\begin{array}{l}\text { Electrical faults caused by generator rotor winding } \\
\text { fault or rotor eccentricity }\end{array}$ \\
\hline $1-10 \mathrm{~Hz}$ & $\begin{array}{l}\text { Faults associated with wind turbine blades or slow } \\
\text { speed shaft }\end{array}$ \\
\hline
\end{tabular}

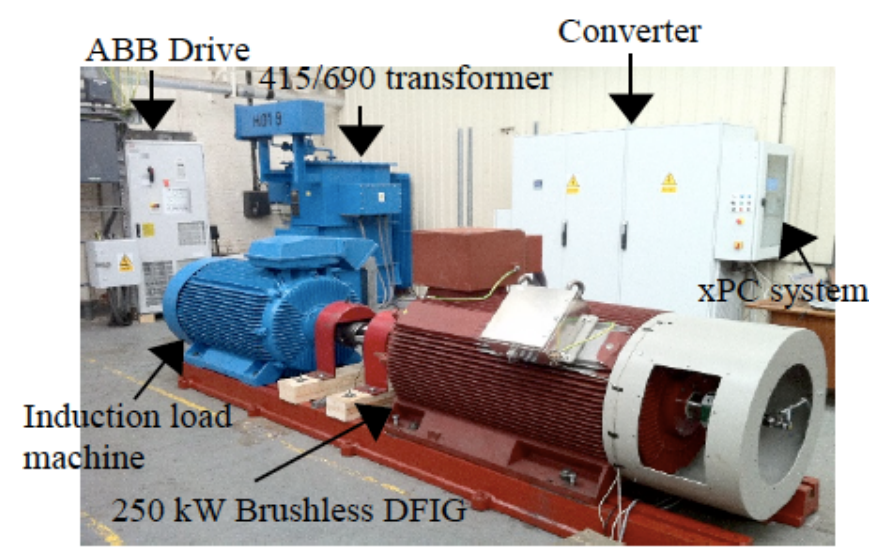

Fig. 4. $250 \mathrm{~kW}$ BDFM on the test bed

TABLE II

KEY SPECIFICATIONS OF THE 250 KW D400 BDFM

\begin{tabular}{ll}
\hline Frame size & 400 \\
Speed range & $500 \mathrm{rpm} \pm 36 \%$ \\
Rated torque & $3670 \mathrm{Nm}$ \\
Rated power & $250 \mathrm{~kW}$ at $650 \mathrm{rpm}$ \\
PW pole number & 4 \\
PW rated voltage & $690 \mathrm{~V}(50 \mathrm{~Hz}$, delta) \\
PW rated current & $178 \mathrm{~A}($ line $)$ \\
CW pole number & 8 \\
CW rated voltage & $620 \mathrm{~V}(18 \mathrm{~Hz}$, delta) \\
CW rated current & $73 \mathrm{~A}($ line $)$ \\
\hline
\end{tabular}

A Simulink model was developed for the $250 \mathrm{~kW}$ BDFM coupled to a gearbox with a ratio of $1: 12$ and three bladed wind turbine with a blade radius $13.5 \mathrm{~m}$. The torque applied to the generator was controlled such that maximum power is extracted from the wind, this corresponds to a tip-speed ratio $(\lambda)$ of 6.2 and a power-coefficient term $\left(c_{p}\right)$ of 0.4 [24]. The generator speed, torque, voltage, current and PW output power were logged using a sampling frequency of $250 \mathrm{~Hz}$.
Using the Simulink model, the steady state performance of the BDFM can be obtained including stator voltages and currents as well as the machine's torque and active and reactive power. The machine's performance obtained from simulation at rated operating conditions are compared with experimental test results in Table III. Close agreement between simulation and test results confirm the validity of the models developed for the prototype BDFM. The operating parameters obtained from the simulation can therefore be used in CWT fault detection of the prototype machine.

TABLE III

STEADy State COMPARISON BETWEEN Simulation AND TEST RESUlTS FOR D400 BDFM

\begin{tabular}{lcc}
\hline Parameters & Simulation & Experiment \\
\hline Speed (rev/min) & 680 & 680 \\
Torque (Nm) & 3696 & 3696 \\
PW voltage (V) & 675 & 675 \\
CW voltage (V) & 691 & 691 \\
PW current (A) & 97.6 & 104.3 \\
CW current (A) & 48.1 & 42.4 \\
Real power (kW) & 252 & 250 \\
PW Reactive power (kVAr) & 55 & 57.1 \\
Efficiency & $95.9 \%$ & $95.0 \%$ \\
\hline
\end{tabular}

\section{FAult Detection IN THE BDFM}

\section{A. Torque Perturbation Fault}

Three sinusoidal torque perturbation faults with different frequencies were applied to the BDFM in Simulink at different time intervals as stated in Table IV.

TABLE IV

TORQue PERTURBAtion FAUlts APPLIED to THE PRototype BDFM SIMULATION MODEL

\begin{tabular}{lcc}
\hline Time interval & Frequency & Amplitude \\
\hline $20-30 \mathrm{Sec}$ & $10 \mathrm{~Hz}$ & $50 \mathrm{Nm}$ \\
$35-40 \mathrm{Sec}$ & $5 \mathrm{~Hz}$ & $100 \mathrm{Nm}$ \\
$45-50 \mathrm{Sec}$ & $50 \mathrm{~Hz}$ & $200 \mathrm{Nm}$ \\
\hline
\end{tabular}

Fig. 5 shows the torque, speed and output power of the BDFM when the faults are applied. As can be seen, the faultperturbations are evident in the generator torque signal. By contrast the PW output power showed only a slight oscillation during the fault. A Fast Fourier Transform (FFT) was performed on the PW power signal in an attempt to identify key fault frequencies and the results are shown in Fig. 6. As can be seen, the fault frequencies cannot be explicitly identified among the other frequencies in the power spectrum. These frequencies are generally associated with the wind turbine mechanical parts as well as the generator especially at low frequencies where the power is changed due to wind speed variations. It is also important to note that the FFT is not time dependent, and so identifying a change in frequency associated with a fault is difficult. 

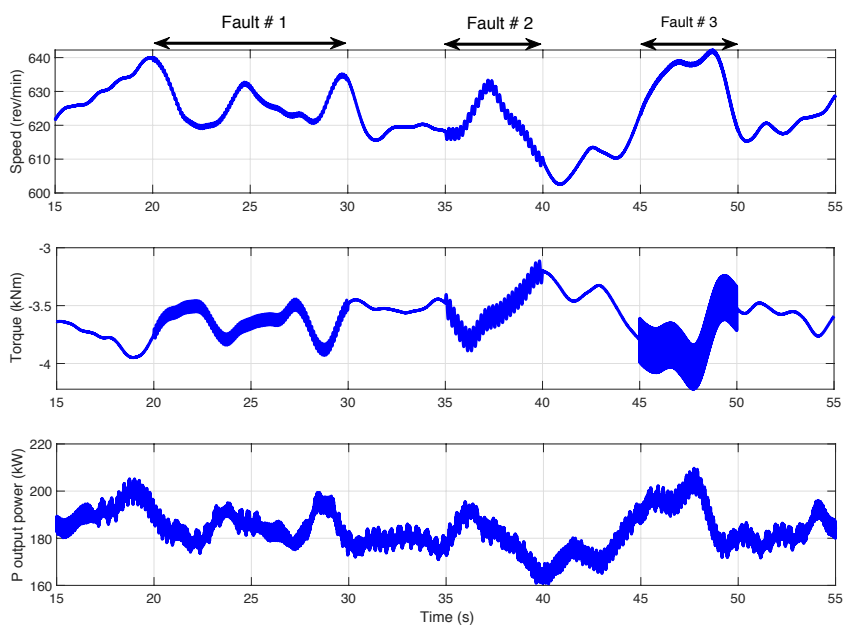

Fig. 5. Speed, torque and PW output power signals when torque perturbation faults are applied.

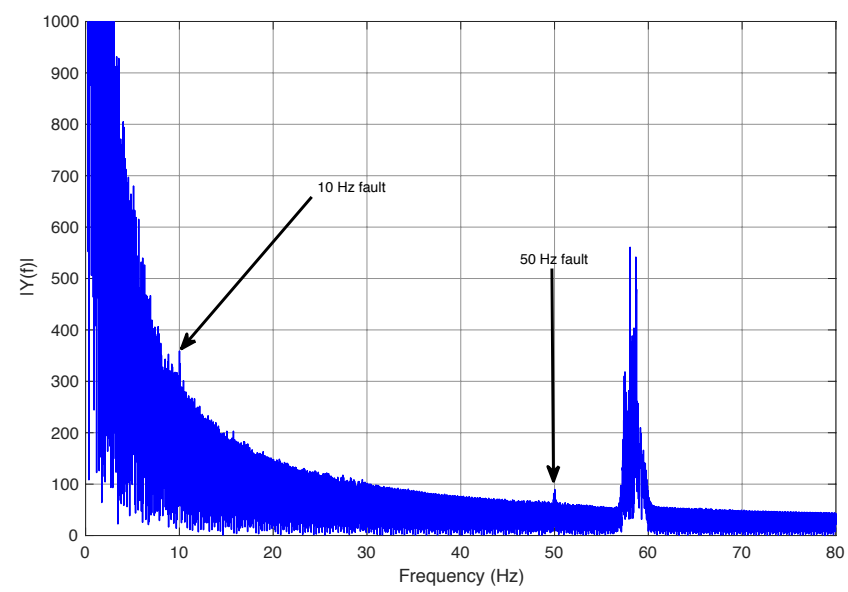

Fig. 6. FFT analysis of the PW output power signa in the presence of the torque perturbation faults.

The CWT analysis described in Section II is applied to the PW output power signal in the presence of the torque perturbation faults. The plot of energy variation is shown in Fig. 7. The same plot is magnified for low frequencies in Fig. 8 . The figures clearly show both the presence and duration of the three torque perturbation faults with 10,5 and $50 \mathrm{~Hz}$ frequencies occurred in the BDFM at the time intervals stated in Table IV. It should be noted that the other low frequencies present in the CWT are due to the slowly varying $(0-2 \mathrm{~Hz})$ output power in response to changes in the wind speed.

\section{B. Rotor Broken Bar Fault}

In this section, a rotor fault was simulated from $t=20-25$ sec, where the resistance of the third bar in the nested-loop rotor [25] was increased to simulate a broken bar as shown in Fig. 9. The currents in the individual rotor bars are shown in Fig. 10. Notice that the current in bar 3 is zero from $t=20-25$ $\mathrm{s}$, while the current in other rotor bars are increased during the same period, reflecting the effect of the broken rotor bar. The CWT analysis for the broken bar fault is presented with the grid overvoltage fault in the next section.

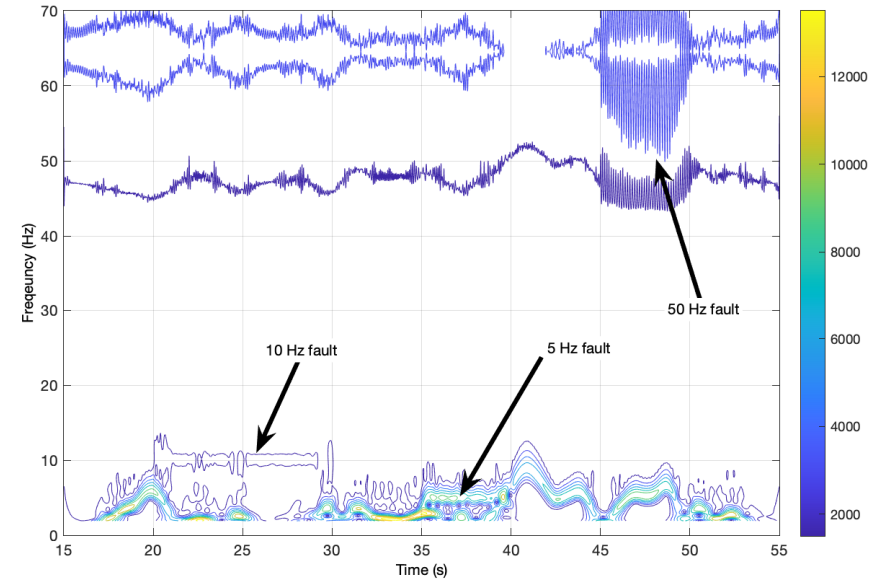

Fig. 7. CWT of PW output power signal in the presence of the torque perturbation faults.

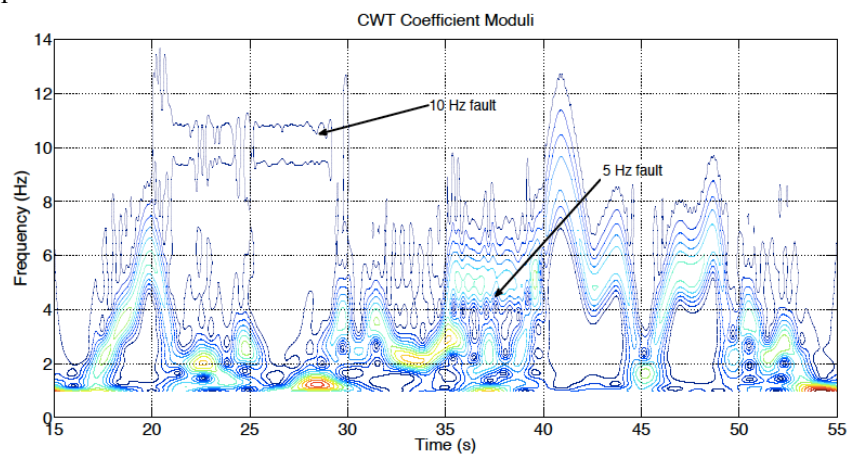

Fig. 8. CWT of PW output power signal, examining the low frequencies

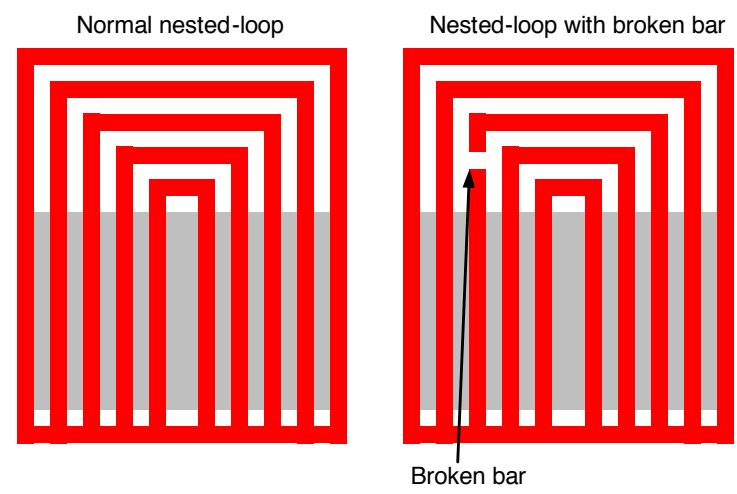

Fig. 9. The nested loop rotor configuration showing the broken bar.

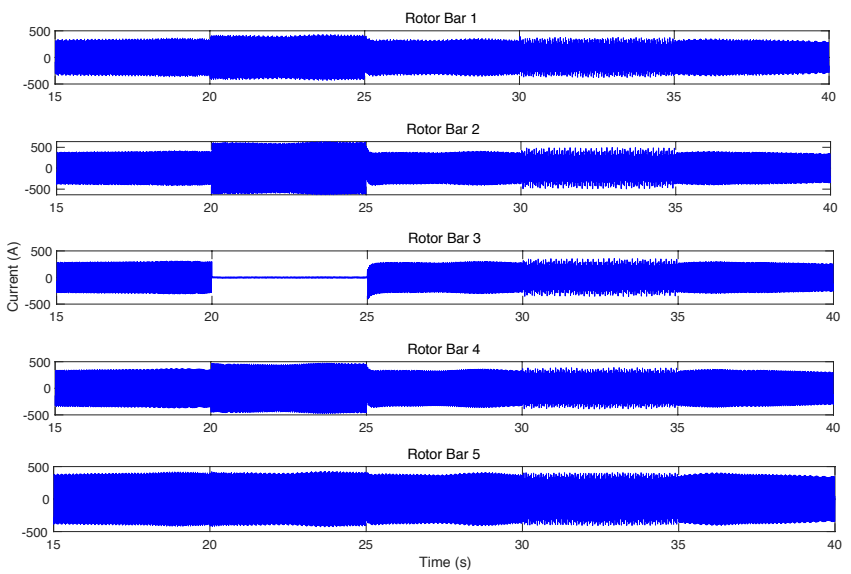

Fig. 10. Rotor bar currents at the event of rotor broken bar fault shown in Fig. 9. 


\section{Stator Grid Overvoltage Fault}

From $t=30-35 s$, a grid fault was simulated, where the amplitude of one of the phases of the $690 \mathrm{~V}$ PW voltage was increased by $10 \%$. The generator speed, torque and PW output power are shown in Fig. 11 when the broken rotor bar fault is occurred during $t=20-25$ and the grid overvoltage fault is occurred during $t=30-35$. The CWT method applied to the PW output power signal are shown in Fig. 12.

The occurrence and duration of the rotor and grid faults are evident in Figure 12, showing the key frequency associated with each fault. From Table I, it is expected to see a fault frequency between $2-50 \mathrm{~Hz}$ corresponding to the rotor broken bar fault, while a fault frequency close to $100 \mathrm{~Hz}$ is expected for the grid voltage fault. This is in agreement with the results of Fig. 12 where $2 \mathrm{~Hz}$ and $100 \mathrm{~Hz}$ frequencies are observed for the durations of 20-25 $s$ and 30-35 $s$, respectively.
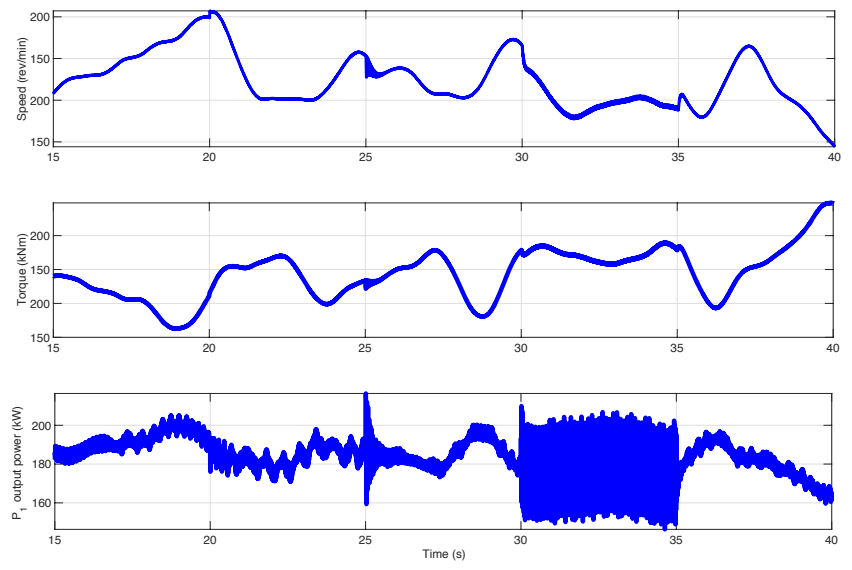

Fig. 11. The BDFM speed, torque and PW output power when $10 \%$ grid overvoltage fault is applied.

\section{CONCLUSIONS}

The BDFM is an attractive generator system for use in wind power generation particularly offshore installations as it offers significant reliability improvement as well as cost reduction when the overall wind turbine drive train is considered. In this study, a continuous wavelet transform (CWT) technique using a wavelet-based adaptive filter has been proposed for the fault detection in a BDFM wind turbine. Three different faults namely rotor torque perturbation, rotor broken bar and grid overvoltage faults have been considered in order to assess the practicality of the proposed method. A $250 \mathrm{~kW}$ BDFM has been considered as the prototype machine in the study.

It has been shown that the CWT technique is capable of detecting all the faults applied to the machine by clearly identifying the associated fault frequencies and duration. It has also been shown that by designing the adaptive filter, the processing time is considerably reduced making the CWT analysis a suitable technique for real-time condition monitoring of the BDFM. Consequently, in comparison with conventional vibration and temperature measurements, and lubrication oil analysis techniques currently being used by the industry, the proposed CWT technique is a low-cost alternative to detect both electrical and mechanical faults in the BDFM.

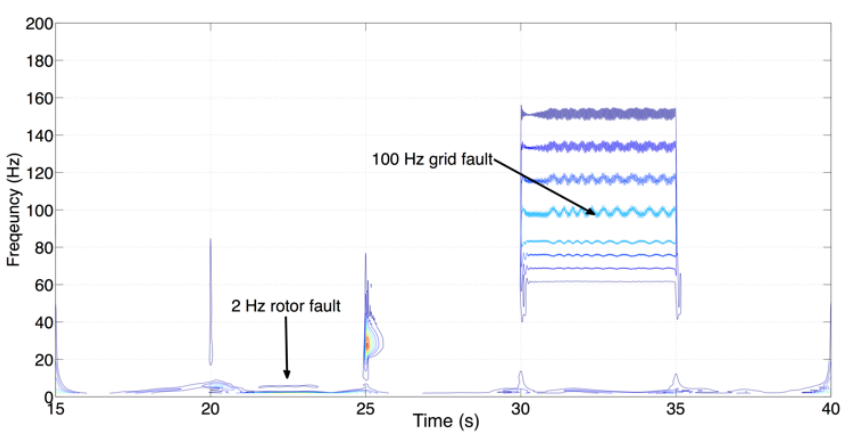

(a)

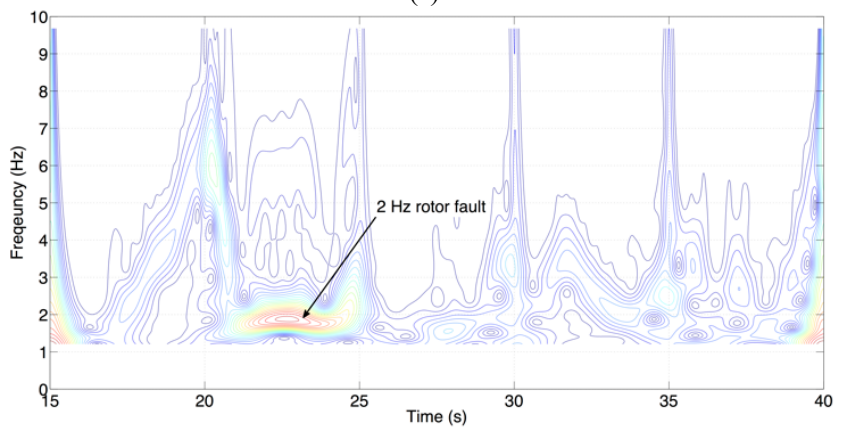

(b)

Fig. 12. CWT of PW output power when rotor broken bar $(\mathrm{t}=20-25 \mathrm{~s})$ and grid voltage faults $(\mathrm{t}=30-35 \mathrm{~s})$ are applied: (a) unmagnified, (b) magnified.

\section{REFERENCES}

[1] Global Wind Energy Council., 'Global Wind Report 2018' (GWEC, 2019), pp. 22-30.

[2] Z. Zhang, A. Matveev, R. Nilssen, A. Nysveen, 'Ironless PermanentMagnet Generators for Offshore Wind Turbines', IEEE Transactions on Industry Applications, Vol. 50, June 2014, pp. 1835-1846.

[3] R. McMahon, X. Wang, E. Abdi-Jalebi, P. J. Tavner, P. C. Roberts, M. Jagiela, 'The bdfm as a generator in wind turbines' Power Electronics and Motion Control Conference, 2006. EPE-PEMC 2006. 12 International, pp. 1859-1865.

[4] A. C. Ferreira, R. M. Stephan, M. Araujo, 'Compensating characteristics of a brushless doubly-fed machine' IEEE International Symposium on Industrial Electronics, vol. 1, 2003, pp. 375-378.

[5] F. Xiong, X. Wang, 'Design and performance analysis of a brushless doubly-fed machine for stand-alone ship shaft generator systems' International Conference on Electrical and Control Engineering, 2011, pp. 2114-2117.

[6] J. Nilsson, L. Bertling, 'Maintenance management of wind power systems using condition monitoring systems-life cycle cost analysis for two case studies', IEEE Transactions on Energy Conversion, vol. 22, no. 1, March 2007, pp. 223-229.

[7] P. J. Tavner, 'Review of condition monitoring of rotating electrical machines', IET Electric Power Applications, vol. 2, no. 4, July 2008, pp. $215-247$.

[8] L. Wang, Z. Zhang, H. Long, J. Xu, R. Liu, 'Wind Turbine Gearbox Failure Identification With Deep Neural Networks', IEEE Transactions on Industrial Informatics, Vol. 13, June 2017, pp. 13601368.

[9] F. Spinato, P. J. Tavner, G. Van Bussel, E. Koutoulakos, 'Reliability of wind turbine subassemblies', IET Renewable Power Generation, vol. 3, no. 4, December 2009, pp. 387-401.

[10] T. Logan, R. McMahon, K. Seffen, 'Noise and vibration in brushless doubly fed machine and brushless doubly fed reluctance machine', IET Electric Power Applications, vol. 7, 2014, pp. 1-10. 
[11] S. Abdi, E. Abdi, R. McMahon, 'A Study of Unbalanced Magnetic Pull in Brushless Doubly Fed Machines', IEEE Transactions on Energy Conversion, vol. 30, 2015, pp. 1218 - 1227.

[12] D. Dorrell, A. Knight, R. Betz, 'Issues with the design of brushless doubly-fed reluctance machines: unbalanced magnetic pull, skew and iron losses', 2011 IEEE Int. Electric Machines and Drives Conf. (IEMDC), 2011, pp. 663-668.

[13] M. Afshar, S. Abdi, M. Ebrahimi, S. Mortazavizadeh, 'Static Eccentricity Fault Detection in Brushless Doubly-Fed Induction Machines based on Motor Current Signature Analysis', 45 th annual conference of the IEEE industrial electronics society, October 2019 , Lisbon, pp. 1369-1374.

[14] M. Afshar, A. Tabesh, M. Ebrahimi, S. Khajehoddin, 'Stator short circuit fault detection and location methods for brushless DFIMs using nested-loop rotor slot harmonics', IEEE Transactions on Power Electronics, December 2019, DOI 10.1109/TPEL.2019.2963295.

[15] B. Jandghi, H. Gorginpour, M. Saket, A. Oraee, M. Ahmadian, H. Oraee, 'A survey on rotor faults in brushless doubly fed machines', $3^{\text {rd }}$ International Youth Conference on Energetics (IYCE), Portugal, 2011.

[16] S. Watson, B. Xiang, W. Yang, P. Tavner, C. Crabtree, 'Condition monitoring of the power output of wind turbine generators using wavelets', IEEE Transactions on Energy Conversion, vol. 25, no. 3, Sept 2010, pp. 715-721.

[17] R. Ibrahim, S. Watson, S. Djurovic, C. Crabtree, 'An Effective Approach for Rotor Electrical Asymmetry Detection in Wind Turbine DFIGs', IEEE Transactions on Industrial Electronics, Vol. 65, No. 11, November 2018, pp. 8872-8881.

[18] J. Chen, J. Pan, Z. Li, Y. Zi, X. Chen, 'Generator bearing fault diagnosis for wind turbine via empirical wavelet transform using measured vibration signals', Elsevier Renewable Energy Journal, Vol. 89, April 2016, pp. 80-92.

[19] B. Tang, W. Liu, T. Song, 'Wind turbine fault diagnosis based on Morlet wavelet transformation and Wigner-Ville distribution', Elsevier Renewable Energy Journal, Vol. 35, 2010, pp. 2862-2866.

[20] W. Yang, P. Tavner, C. Crabtree, M. Wilkinson, 'Cost-effective condition monitoring for wind turbines', IEEE Transactions on Industrial Electronics, vol. 57, no. 1, Jan 2010, pp. 263-271.

[21] J. Ribrant, L. Bertling, 'Survey of failures in wind power systems with focus on Swedish wind power plants during 1997-2005', IEEE Transactions on Energy Conversion, vol. 22, no. 1, March 2007, pp. 167-173.

[22] W. Yang, P. Tavner, C. Crabtree, 'An intelligent approach to the condition monitoring of large-scale wind turbines', European Wind Energy Association Conference, France, 2009.

[23] R. McMahon, P. Tavner, E. Abdi, P. Malliband, D. Barker, 'Characterising brushless doubly fed machine rotors', IET Electric Power Application, vol. 7, 2013, pp. 535-543.

[24] D. Llano, M. Tatlow, R. McMahon, 'Control algorithms for permanent magnet generators evaluated on a wind turbine emulator test-rig', 7th IET International Conference on Power Electronics, Machines and Drives (PEMD), April 2014, pp. 1-7.

[25] R. McMahon, P. Tavner, E. Abdi, P. Malliband, D. Barker, 'Characterising brushless doubly fed machine rotors', IET Electric Power Applications, vol. 7, no. 7, Aug 2013, pp. 535-543.

\section{BIOGRAPHIES}

Salman Abdi received the B.Sc. degree from Ferdowsi University, Mashhad, Iran, in 2009, and the M.Sc. degree from the Sharif University of Technology, Tehran, Iran, in 2011, both in electrical engineering. He then completed the Ph.D. degree in electrical machines design and modeling from Cambridge University, Cambridge, U.K, in 2015. He is currently an Assistant Professor in Electrical Engineering at the University of East Anglia (UEA), Norwich, UK. His main research interests include electrical machines and drives for renewable power generation and automotive applications.

Ehsan Abdi (SM'12) received the B.Sc. degree from the Sharif University of Technology, Tehran, Iran, in 2002, and the M.Phil. and Ph.D. degrees, from Cambridge University, Cambridge, U.K., in 2003 and 2006 , respectively, all in electrical engineering. He is currently the Managing Director of Wind Technologies Ltd., Cambridge, where he has been involved with commercial exploitation of the brushless doubly fed induction generator technology for wind power applications. He became a Senior
Member of the IEEE in 2012. His main research interests include electrical machines and drives, renewable power generation, and electrical measurements and instrumentation.

Richard McMahon received the B.A. degree in electrical sciences and the Ph.D. degree from the University of Cambridge, Cambridge, U.K., in 1976 and 1980, respectively. Following postdoctoral work on semiconductor device processing, he became a University Lecturer in electrical engineering in 1989 with the Engineering Department, University of Cambridge, where he was a Senior Lecturer in 2000. In 2016, he was with the Warwick Manufacturing Group, University of Warwick, Coventry, U.K., as a Professor of power electronics. His current research interests include electrical drives, power electronics, and semiconductor materials.

Sam Amiri received his B.Sc. degree in Software Engineering from Azad University, Tehran, Iran, in 2007. He later received his M.Sc. degree in Embedded Systems from Masaryk University, Brno, Czech Republic, in 2010, and his Ph.D. degree in Electrical Engineering from the same institution in 2014. He then continued as a Researcher at Queen's University Belfast in 2015-2017, and later at University of Bristol in 2017-2018. He is currently a Lecturer in Analogue and Digital Electronics at Coventry University, Coventry, UK. His main research interests include hardware design, embedded systems, and signal and image processing. 